\title{
MAURA LOPES CANÇADO: CONSIDERAÇÕES EM TORNO DO INÍCIO DA LITERATURA FEMININA AUTOBIOGRÁFICA NO BRASIL
}

\author{
MAURA LOPES CANCADO: CONSIDERATIONS ABOUT THE \\ BEGINNING OF AUTOBIOGRAPHICAL FEMININE LITERATURE IN \\ BRAZIL
}

\author{
Márcia Moreira CUSTÓDIO ${ }^{1}$ \\ Alex Fabiano Correia JARDIM ${ }^{2}$
}

\begin{abstract}
RESUMO: A proposta do texto é problematizar a literatura feminina no Brasil, em especial aquela de perspectiva autobiográfica. Esse 'estilo' de escrita em Maura L. Cançado nos mostra que neste gênero a literatura se mistura com o próprio ato de escrever, um tipo de murmúrio estranho que não se restringe a uma mera consciência crítica. E é pela escrita de Hospício é deus - diário I (1965) e de O sofredor do ver (1968) que a escritora faz uma consagração das palavras e expressa, a partir daquilo que a transvasa, sua inquietude em relação ao mundo, às pessoas, às relações. Em Maura, a "palavra literária é um "arrombamento"', escapando-se das limitações da mera linguagem formal. Nesse sentido, Maura escapa a uma busca pela verdade ou estabelecimento de uma metanarrativa e se insurge no direito de falar, de instituir um território, um possível qualquer. É a partir desse fio condutor que pensaremos a obra de Maura Lopes Cançado, enfatizando a relação entre escrita ficcional e autobiográfica, indicando de que modo autora e personagem se imbricam e expressam sentimentos em relação a uma determinada ordem constituída e estabelecida.
\end{abstract}

PALAVRAS-CHAVE: Literatura feminina. Escrita de si. Maura L. Cançado. Literatura autobiográfica. Loucura.

\begin{abstract}
The aim of this text is to problematize the feminine literature in Brazil, especially that of autobiographical perspective. This 'style' of writing in Maura L. Cançado shows us that, in this genre, there is a fusion between literature and the act of writing, a kind of strange murmur that it is not reduced to mere critical awareness. And it is by the writing of Hospício é deus - diário I (1965) and $O$ sofredor do ver (1968) that the writer makes a consecration of the words and expresses, from what exceeds herself, her discomfort in relation to the world, to the people, to the relations. In Maura, the "literary word is a breaking-in', that exceeds the limitations of the mere formal language. Thus, Maura escapes a search for the truth or establishment of a metanarrative and claims for herself on the right to speak, to establish a territory, a possible any. It is from this guideline that we are going to think about the work of Maura Lopes Cançado, emphasizing the relation between fictional and autobiographical writing, indicating how author and character interlock themselves and express feelings in relation to a certain constituted and established order.
\end{abstract}

KEYWORDS: Female literature. Self writing. Maura L. Cançado. Autobiographical literature. Madness.

\footnotetext{
${ }^{1}$ Doutora em Letras/Estudos Literários pela Universidade Federal do Espírito Santo (Brasil). Professora do Ensino Básico, Técnico e Tecnológico (EBTT) do Instituto Federal do Triângulo Mineiro (IFTM/Campus Avançado Uberaba Parque Tecnológico). marciamcustodio72@gmail.com

2 Doutor em Filosofia. Professor do Mestrado em Letras/Estudos Literários e do Mestrado Profissional em Filosofia da Universidade Estadual de Montes Claros. alex.jardim38@ hotmail.com
} 


\section{Sobre uma literatura obscena}

Na superfície narrativa das obras da escritora mineira Maura Lopes Cançado (19291993), ficção e realidade imbricam-se de tal modo que a escrita se irrompe como devir. Por meio da escrita de uma obra autobiográfica construída durante uma de suas internações no hospício, Maura não apenas realiza a correspondência entre o hospício e o mundo, como também se constitui em uma estética da existência na qual a própria vida se (re)cria, abrindo espaço para uma reflexão sobre a relação entre literatura e loucura. Conforme explicita Custódio (2017), em Hospício é deus - diário I (1965), há uma narradora cujo “propósito como louca é antes apresentar, a partir de sua situação de hospiciada, o débil quadro clínico de nossa cultura" (CUSTÓDIO, 2017, p. 16).

Tendo sua vida marcada por internações em clínicas psiquiátricas, a temática da loucura em suas obras demarca o seu lugar na sociedade do seu contexto, tanto como escritora como o de mulher louca. Afastada de seus pares, na arena literária e na vida comum, "essa escritora mineira, personagem de sua narrativa, ajusta-se no desvio que se efetiva em suas obras, tidas como incompletas, inacabadas, passíveis de serem lidas como produto de uma mente desviante, louca e doente" (CUSTÓDIO, 2017, p. 16).

Constituindo-se uma produção representativa da literatura nacional contemporânea, a parca produção crítica a respeito de suas obras confirma seu lugar de obscena, compreendido aqui como aquela que está fora de cena, ocupado por Maura na arena literária por muitos anos. Contudo, no atual cenário acadêmico, percebe-se a valorização de sua escrita, constatada pelos trabalhos de cunho expressivo sobre suas duas obras. Essa (re)descoberta da literatura da Maura Lopes Cançado não implica apenas um olhar mais atento às suas qualidades estéticas na escrita, mas sua obra revela a necessidade de um olhar crítico a respeito dos discursos que se produziram historicamente sobre a loucura e, sendo a literatura esse espaço em que existe a busca de uma transversalidade em relação aos discursos que imprimem exclusão e interdição, é locus importante para uma análise mais atenta às instâncias de controle que se expressam através de espaços fechados de enclausuramento, dando a certos saberes um campo visível e material de ação, além de uma profunda apropriação da verdade sobre a ordem das coisas e dos homens.

Sua primeira obra, Hospício é deus - diário I, trata-se de um livro-diário no qual encontraremos, nas primeiras páginas, um forte relato da sua vida, da infância até a mudança 
para o Rio de Janeiro, quando tinha 22 anos. Depois as anotações são marcadas por datas que vão de 25 de outubro de 1959 a 7 de março de 1960. Como disse a própria narradora Maura, aos 19 anos, foi internada pela primeira vez, em Minas Gerais, mesmo estado em que nasceu. A coletânea de contos O sofredor do ver (1968), sua segunda e última obra, constitui-se de uma compilação de contos que haviam sido publicados no Jornal do Brasil e no Correio da Manhã.

As duas obras trazem marcas da vida de uma menina que nasceu em uma rica fazenda próxima ao município de São Gonçalo do Abaeté, no Alto São Francisco, Minas Gerais, mas que teve um final trágico, esquecido entre hospícios e prisões psiquiátricas. No entanto, se foram essas internações que, na literatura, a inseriram em uma rede estigmatizada pelo desvio, foram estas que serviram de solo para a escrita de suas obras. Portanto, é a partir daí que brota a reflexão sobre desvio:

É possível refletir sem pensá-lo como deformidade, anomalia ou falta? É neste sentido que a situação de Maura mais uma vez se apresenta, por excelência, como o não-lugar de irrupção de uma concepção de literatura do desvio, pois, enquanto uma desviada, confinada, pode dar a ver a discursividade de seu intento, a possibilidade de se falar sobre a própria loucura da experiência ocidental, exercendo sua plena liberdade (CUSTÓDIO, 2017, p. 17).

Com as obras de Maura, essa reflexão é possível, uma vez que o lugar de produção, o hospício, é potencializado em espaço de criação e assunto para suas obras. Vê-se, assim, um contraponto: é possível haver criação na loucura? Ora, na dinâmica do trânsito da palavra para o discurso ficcional “o factual é submetido à palavra literária, desconstrói-se o nome próprio, deixando dele apenas rastro, permitindo, desse modo, a abertura de cadeias significantes" (CUSTÓDIO, 2017, p. 31). Desse modo, segundo Deleuze, a literatura aparece

\footnotetext{
como um empreendimento de saúde; não que o escritor tenha forçosamente uma saúde de ferro (haveria aqui a mesma ambiguidade que no atletismo), mas ele goza de uma frágil saúde irresistível, que provém do fato de ter visto e ouvido coisas demasiado grandes para ele, fortes demais, irrespiráveis, cuja passagem o esgota, dando-lhe contudo devires que uma gorda saúde dominante tornaria impossíveis (DELEUZE, 1997, p. 13-14).
}

Nesse sentido, o texto da Maura transforma-se em uma composição bastante intrigante entre realidade e ficção, em uma clara demonstração de que a sua criação literária caminhará na tênue linha entre experiência e invenção, sem que essa última necessariamente desqualifique a força da experiência, afinal, ela é o elemento fundamental para a construção do seu texto. A respeito de seu diário, Lúcia Castelo Branco afirma: 
O texto de Maura se escreve, dessa forma, à margem, no limiar, nos limites de um entrelugar. Além de diário, é diário de uma ficcionista - o que recebemos como realidade, como confissão, pode não passar de ficção, habilmente trabalhada pela voz de sua narradora (CASTELLO BRANCO, 2004, p.164).

Por isso, a escrita de Hospício é Deus, por exemplo, escapa a qualquer necessidade de meramente falar de si, muito menos pretende fazer um simples conjunto de apontamentos histórico-pessoais acerca da loucura. A escrita de caráter autobiográfico, desse modo,

\begin{abstract}
é uma artimanha, uma estratégia para dar vazão ao fluxo da experiência-limite. Não se trata, e é importante ressaltar isso, de uma ruptura com o real. Contrariamente, é um mergulho no próprio real, na vida, tal qual ela se apresenta e no embate com a sociedade e tudo aquilo que a constitui no período: a psiquiatria enquanto uma ordem do saber, a noção de família e o manicômio. Instituição-maior na intenção de confinar os chamados inadaptados, perigosos e loucos (JARDIM; MAIA, 2015, p. 63-64).
\end{abstract}

Por trazer à tona situações de desvios dos "normais" e condições desumanas dos “anormais", a leitura das obras de Maura leva ao desconforto, à sensação de culpa para a qual não há perdão. Compactua-se com a dor, com o silêncio de um tempo que lançou o louco ao extremo da invisibilidade da história do seu tempo. As obras de Maura abrem uma fissura no tradicionalmente aceito, transgridem as normas, são loucuras. Uma louca irrompe no espaço literário com obras que constituem loucura, pois

pela loucura que a irrompe, uma obra abre um vazio, um tempo de silêncio, uma questão sem resposta, provoca um dilaceramento sem reconciliação onde o mundo é obrigado a interrogar-se. $\mathrm{O}$ que existe de necessariamente profanador numa obra retorna através disso e, no tempo que essa obra desmoronou no silêncio, o mundo sente sua culpabilidade (FOUCAULT, 2010, p. 529-530).

De um modo difícil, portanto, a reflexão sobre a produção literária de Maura demanda leituras e percepções que dizem respeito a um objeto específico, ao mesmo tempo em que leva a uma análise generalista. A respeito da especificidade de suas obras, Custódio destaca particularidades como

o objeto em si - seu espaço de produção, a autoria louca, a autoficcionalidade, sua perspectiva corporal de produção e vanguardismo; e a generalidade diz respeito ao estudo do papel desse mesmo objeto dentro da história literária como um todo contexto de produção e recepção da obra (CUSTÓDIO, 2014, p. 13).

Ora, o incômodo extraído da leitura e recepção de suas obras tem suas bases na realidade, na difícil relação social entre o "normal” e o "diferente", que levou à reivindicação de medidas políticas de higienização que culminaram em confinamento do louco em espaços nos quais era submetido a práticas de violência e de invisibilidade social. Esse parêntese na história, ainda carente de aprofundamento crítico, reforça a importância da investigação das obras de Maura e 
ressalta o inquestionável papel artístico da escritora. Não obstante, é pelo viés literário que ela procurará caracterizar cada etapa no hospício (espacialidade que habitam justamente os que estão fora de cena), "enfatizando que a loucura foi sendo constituída a partir de jogos de verdade em torno de si, isto é, um conjunto de práticas médicas com o objetivo de fundamentar princípios de inteligibilidade" (JARDIM; MAIA, 2015, p. 67).

Sobre a recepção de Maura por seus pares, conforme explicita Custódio, no contexto em que a escritora está inserida, o acolhimento

\begin{abstract}
é brando, sem, contudo, ser livre de preconceitos". Observa-se que, como na atualidade, o terreno literário era mais ocupado por homens. Ainda hoje o contingente masculino segue sendo hegemônico. Tal fato se verifica nos catálogos das editoras, nos resultados dos prêmios literários concedidos, nos programas dos cursos de Letras e na lista de convidados para as festas literárias que ocorrem no país. Embora essa presença masculina se desse com maior visibilidade nos anos 1950, não serviu de empecilho para a criação da obra Maura, porque escrever, para ela, era uma necessidade vital, portanto, inevitável (CUSTÓDIO, 2014, p. 28-29).
\end{abstract}

Há que se ressaltar que a escolha por uma escrita autobiográfica aliada à temática da loucura afastou-a, portanto, de escritoras contemporâneas a ela, como Clarice Lispector, Lygia Fagundes Telles, entre outras. Contudo, se sua obra, construída de forma híbrida (memória e diário), afetou negativamente na sua aceitação nos círculos literários, tal escolha conferiu-lhe uma expressiva autonomia na criação, delineando, assim, um novo perfil de escritora feminina na literatura brasileira: o da escritora louca.

Assim, ainda que para Maura a loucura se apresente calcada pelo isolamento, essa solidão significaria de alguma maneira uma liberdade, uma forma de subversão à lógica da razão dominante. Desse modo, Maura é um dos poucos exemplos da literatura do fracasso das relações sociais estabelecidas, engessadas em modelos e perspectivas. Suas obras são o 'devirlouco'3 que se apresenta enquanto condição de crítica ao próprio meio, à sociedade e suas exigências.

Nas obras de Maura, portanto, mais especificamente em seu diário, faz-se necessário compreender que, uma vez potencializadas pelo meio, suas narrativas, metonimicamente, apresentam-se em forma de um corpo inevitavelmente marcado pelo espaço da loucura, levando a uma ruptura com a forma tradicional da escrita. Do mesmo modo que apontam as reflexões

\footnotetext{
${ }^{3}$ Segundo Deleuze e Guattari, "devir é, a partir das formas que se tem, do sujeito que se é, dos órgãos que se possui ou das funções que se preenche, extrair partículas, entre as quais instauramos relações de movimento e repouso, de velocidade e lentidão, as mais próximas daquilo que estamos em vias de devir, e através das quais devimos. É nesse sentido que o devir é o processo do desejo" (DELEUZE; GUATTARI, 1997, p. 64). Nesse sentido, o objetivo do devir é abrir para a criação de novos territórios, abrir para a criação de novas subjetividades.
} 
de Jardim e Maia (2015, p. 72) a respeito de Lima Barreto, nesse contexto, a obra de Maura L. Cançado invoca o louco à fala, a produzir discurso. O louco (como a autora em questão) “também pode tornar dizível aquilo que até então estava mudo, silenciado. Não se trata de um discurso desprezível, estranho ou ininteligível” (JARDIM; MAIA, 2015, p. 72). Com efeito, significa a entrada do "obsceno" na arena literária, ou seja, o louco, que estava fora da cena literária, não apenas se insere, mas traz um pensamento "diferente daquela consciência médica fundamentada no discurso epistemológico habituada no binarismo erro e verdade, [...] herdeiro do século XVII e XVIII, que classificava, observava, media, extraía um enunciado e determinava um objeto" (JARDIM; MAIA, 2015, p. 72). Contrariamente, Maura e sua literatura descrevem a loucura como um tipo de linguagem secreta do delírio.

No que tange à Literatura, compreende-se, portanto, que Maura abre um hiato na história literária. Suas obras não apenas rompem no gênero e com a temática engajada de seu tempo, mas, produtivamente, inauguram a escrita feminina louca na literatura brasileira. Como explica Custódio,

\begin{abstract}
$\mathrm{Na}$ literatura diarística de autoria feminina no Brasil, embora encontremos muitos nomes importantes, com leitores numerosos e vastos trabalhos acadêmicos sobre a produção literária do gênero, a questão da restrita presença de publicações de produções de autoria feminina louca, entretanto, não esconde que são ainda poucas as escritoras diagnosticadas loucas que têm acesso ao espaço literário. Por outro lado, como se afirmou anteriormente, há pouca visibilidade para esse tipo de produção de escrita feminina, ou seja, ainda que tímida, existe essa produção, porém tem recebido pouca atenção da crítica especializada, o que leva muitas vezes ao seu silenciamento (CUSTÓDIO, 2014, p. 21).
\end{abstract}

O valor de Maura não reside apenas na especificidade do gênero adotado em sua escrita. Sua singularidade deriva de uma escrita marcada pelo diálogo com a pós-modernidade, uma vez que a mescla de gêneros advém da tensão entre subjetividade-objetividade, entre o real e o ficcional, entre passado e presente, entre loucura e sanidade. Em Maura, os traços estilísticos decorrem do tenso diálogo entre língua e experiência.

\title{
2 Sobre Hospício é deus - diário I
}

A escrita autobiográfica de Maura afasta-se da tradicional escrita de si feminina por tratarse de uma louca produtiva que compreende o seu lugar à margem, mas que mantém uma postura de resistência, fugindo dos lugares socialmente determinados. Seu diário é um imbricado ir e vir, no qual a seleção da memória a ser narrada emerge a partir de sensações exteriores à 
situação no presente do hospício. Esse trânsito é marcado por eventos reais do passado, como também situações vividas na realidade do presente, conforme informa Custódio:

\begin{abstract}
Iniciando com um retorno no labirinto da memória, a mira de Hospício é deus recai sobre a própria autora, que recolhe fragmentos de si mesma, numa busca obcecada por reconstituir sua vida e ocupar os espaços vazios, deteriorados. Logo em seguida, a narrativa do passado costura-se ao presente, combinando dois gêneros, memória e diário. Na memória, Maura narra eventos ocorridos na infância e adolescência e confronta-os com a situação atual do cotidiano do hospício vivido pela escritora, perfazendo uma montagem de quebra-cabeças. Uma ponte une dois extremos: o passado glorioso e o presente sombrio (CUSTÓDIO, 2017, p. 30).
\end{abstract}

A sua produção estética revela um modo dolorido de "reorganização e percepção do mundo exterior, devido à sua experiência de hospiciada e seu desajustamento com o mundo" (CUSTÓDIO, 2014, p. 26). Essa consciência não lhe traz conforto, mas confere-lhe resiliência:

Devo escrever sempre no princípio de cada página do meu diário que sou uma psicopata. Talvez essa afirmação venha despertar-me, mostrando a dura realidade que parece tremular entre esta névoa longa e difícil que envolve meus dias, me obrigando a marchar, dura e sacudida - e sem recuos (CANÇADO, 1991, p. 71).

Por situar-se no lugar de escritora louca, longe de engajar-se em propostas circunscritas aos interesses de um momento histórico dado, seu objeto artístico não é produto derivado de modismos temáticos, mas é, sobretudo, expressão e apreensão genuína de sua experiência no hospício. No discurso estético e na linguagem da loucura de Maura vislumbra-se uma corrente viva de criação: percepção e memória sensoriais exacerbadas, indicativos de um vertiginoso movimento em que a criação literária vai organizando um certo teatro e montando as peças do jogo, a tal ponto de a escritora se vê imersa, dobrada e redobrada em sua própria criação. Engolida por ela. Conforme afirma Custódio,

no relato de Hospício é deus há um apelo de verdade e, por ser em primeira pessoa do singular e apresentar uma narradora com mesma identidade nominal da autora, tendese a confundir autor e personagem. Sendo um eu dirigindo seu discurso a um tu, que é o leitor, a narradora/protagonista ancora o sistema verbal no tempo presente da fala, ora desdobrando-se para o passado, ora para o futuro. Vez ou outra lança interrogações ou ordens, demonstra asserções ou incertezas, a respeito das quais induz uma resposta por parte do leitor (CUSTÓDIO, 2017, p. 31).

Diante disso, Hospício é deus - diário I pode ser compreendido como a obra pioneira da escrita autobiográfica de autoria feminina louca na literatura brasileira. Sua leitura demanda não apenas mobilizar as forças da historiografia literária, mas, principalmente, trazer reflexões sobre as condições de produção e, consequentemente, sob quais circunstâncias a escrita foi possível. 
Como uma onda que nos arrasta e sacode em direção à desagregação, ao caos e à morte, Hospício é deus lança-nos para um novo, para uma verdade dolorosa que aniquila: "Estou de novo aqui, e isto é Por que não dizer? Dói." (CANÇADO, 1991, p. 28). Por não apresentar propostas de uma época cuja senha para o reconhecimento literário seria um trabalho de teor feminista ou sobre temas mais ou menos politicamente engajados, vê-se então que Maura constitui-se como irrupção, encerrando uma dimensão paradoxalmente produtiva da criação artística para o seu momento histórico. Afinal, para Maura, escrever sobre si-mesmo (trata-se de uma mulher que escreve) é condição para que continue viva. No texto autobiográfico da autora, a escrita de si é a forma pela qual ela encontra no exercício do pensamento uma maneira de fazer da própria vida um problema.

\footnotetext{
Mal posso escrever. O lápis está tão pequeno que não consigo segurá-lo bem. Não tivemos luz das sete horas até agora. Sem ler nem escrever vi-me em pânico [...] Aqui é difícil viver; estou completamente vencida, se me volto para o passado é pior ainda: fui eu? Ou, sou eu? Então caminhei para isto? Ontem pareceu-me ter chegado ao fim - pensei honestamente em matar-me. Continuo pensando. Não sei por que ainda não o fiz, já que não encontro outra saída (CANÇADO, 1991, p. 166).
}

Percebe-se, portanto, uma narradora que faz um apelo a um pensamento mais potente, uma vez que é o sofrimento o que está em jogo. Assim, há uma mão que “experimenta, em certos momentos, uma enorme necessidade de agarrar: ela deve agarrar o lápis, tem de fazê-lo, é uma ordem, uma exigência imperiosa" (BLANCHOT, 2011, p. 15-16).

Contudo, por ser a mão uma metonímia de um corpo que passa por experiências traumáticas no hospício, Maura é arrastada à escrita, num movimento de dobra do pensamento de Maura escritora sobre ela mesma, cuja "necessidade seria antes a de escapar àquilo que é sem direito, sem justiça e sem medida" (BLANCHOT, 2005, p. 41).

É importante ressaltar, para fins de estilo da escrita, que sua narrativa, pela maneira como a "história" é contada por Maura, está toda ela impregnada pela descontinuidade, pelo vacilo, pelas "idas e vindas" no tempo. Um tipo de memória disjuntiva em que a intensidade fala mais alto do que a cronologia e a linearidade dos fatos, tal como é narrado:

Incapacidade quase total de escrever. Lapsos. Terei resistência para escrever um romance? Há longos vazios em minha mente que tornam difícil formular uma história. Se me fosse possível escrever mais rápido, e sem as interrupções. Estou sempre cansada, disposta a deixar tudo para começar depois. Quando? Me pergunto.

Conheço muito bem as 'auras' epiléticas. Elas me são cotidianamente familiares, impedem-me grandes trabalhos intelectuais. Estes sintomas indescritíveis formam quase que meu dia-a-dia (CANÇADO, 1991, p. 124). 
Nota-se que a memória de Maura é instável, maleável, renunciando à temporalidade linear em proveito dos tempos múltiplos, nos níveis em que o tempo e espaço se enraízam nos eventos do corpo. E é entre crises e surtos psicóticos que se ergue a obra, meio possível de se resistir ao Fora. Pelbart (1993) explica a diferença entre o pensamento do Fora e a loucura:

$\mathrm{Na}$ loucura, o sujeito ficaria exposto sem proteção alguma à violência desse Fora, e sem condições de estabelecer com ele um vaivém ou uma relação. Abertura máxima ao Fora, e ao mesmo tempo extravio no temporal abstrato, que é sua marca. (PELBART, 1993, p. 97)

Metaforizado no pátio, Fora é o espaço da morte, ou seja, é o lugar onde as loucas permanecem "mudas, incomunicáveis, olhando nada aparentemente, talvez percebendo em excesso" (CANÇADO, 1991, p. 146). Por isso, resistindo à loucura, Maura escreve, fazendo disso uma relação de vaivém com o Fora e com a "morte", pois, sem obra, não há retorno. Daí o pavor quando ia ao pátio: "Estou desesperada. Sempre fico assim quando vou lá. Tenho medo. Não frequento o pátio [...]. Mas até quando vai durar isto? Até quando estarei livre do pátio?” (CANÇADO, 1991, p. 148).

Em Maura, há uma narradora que expressa o mundo do hospício do modo como esse mundo se expressa para ela:

O hospício é árido e atentamente acordado. Em cada canto, olhos cor-de-rosa e frios
espiam sem piscar. Os dias neutros. As tardes opacas, vazias, quando um ruído
assusta, como vida, surgida rápida, logo apagada - extinta. As mulheres presas no
pátio deixam as seções quase vazias; poucas permanecem, como eu, aqui dentro o dia
todo. Não frequento o pátio e isto me dá, ainda aqui, e usando o uniforme do hospital,
a sensação de estar à margem (CANÇADO, 1991, p.71).

Se o hospício é descrito como árido, frio e assustador, a descrição do pátio não é diferente. A todo custo esse espaço da alienação é mantido à distância pela narradora, para não cair no enredamento do sistema. A narradora luta para se juntar às outras no "pátio", atenta para não se perder. O hospício de palavras emerge na obra de maneira personificada, com vida, é um ser brutal que espia, sempre atento, ávido por levá-la ao "pátio". No entanto, o corpo da narradora expressa-se com negatividade, recusando-se a entregar-se a ele, sabendo que são poucas as que permanecem fora do pátio. Esse hospício terrível e temível é também um corpo expressivo.

Estou de novo aqui, e isto é Por que não dizer? Dói. Será por isto que venho? - Estou no Hospício, deus. E hospício é este branco sem fim, onde nos arrancam o coração a cada instante, trazem-no de volta, e o recebemos: trêmulo, exangue - e sempre outro. Hospício são as flores frias que se colam em nossas cabeças perdidas em escadarias de mármore antigo, subitamente futuro - como o que ainda não se pode compreender. São mãos longas levando-nos para não sei onde - paradas bruscas, corpos sacudidos se elevando incomensuráveis: Hospício é não se sabe o quê, porque Hospício é deus (CANÇADO, 1991, p. 28). 
Marcadas pela primeira pessoa e tempo verbal no presente, as metáforas referentes ao hospício revelam a experiência de um agora negativo e agônico na voz de um sujeito que constrói a imagem do hospício pela percepção carnal com que este se lhe apresenta.

Em oposição a essa imagem dolorida, curiosamente, no início do diário, há uma longa narrativa memorialística, livre de datas, na qual a narradora traz reminiscências de um tempo glorioso, a infância vivida na fazenda, rodeada de cuidados. Percebe-se nessas primeiras linhas uma protagonista tentando justificar sua atual situação, sem, contudo, imputar-se culpa. Nesse momento, responsabiliza a maneira como fora educada por moldar-lhe o caráter excêntrico, ou a genialidade. É um meio criativo de angariar a compreensão do leitor, ou até mesmo de amenizar sua impotência diante da atual condição de louca institucionalizada:

Estarei sendo severa comigo mesma? Teria sido diferente meu modo de ser se meus pais soubessem orientar-me? Naturalmente sim, creio. Eram simples demais para lidar comigo, eu possuía imaginação acima do comum, era inteligente, ambiciosa - e nada prática. Isso os desnorteava. Evidentemente, já se manifestava em mim um temperamento paranoide. Uma boa orientação, entretanto, podia ter corrigido esse defeito de personalidade. Ou não? Teria atingido o que eles jamais poderiam alcançar? Estaria deslocada no meio deles? Acredito que sim, e os fatos provam. Verdade que adquiri (não sei como), liberdade total em relação a tudo e todos que cercavam, desde a mais pequena infância. Faltavam-me meios para fugir àquele clima de asfixia. Então eu sonhava (CANÇADO, 1991, p. 24).

Nessa viagem memorialística, sem datas, a narradora apega-se a momentos efêmeros, marcados por experiências doces, contrárias às vividas na situação do presente da escrita. Mas é ainda nessa parte da memória que dá início ao relato do presente, "é a terceira vez que me encontro no hospital. O número de doentes é grande e poucos são os loucos" (CANÇADO, 1991, p. 29).

Há outro momento em que a narradora relata a visão romântica que tinha sobre o hospício antes de internar-se. O ano era 1949, Maura residia em Belo Horizonte e estava com 19 anos, idade em que ocorrera sua primeira internação em clínica psiquiátrica, a partir da qual dá início a uma série de sucessivas passagens por sanatórios.

\footnotetext{
Nesta época internei-me pela primeira vez em sanatório para doentes mentais. (Já eu tinha dezoito anos). Ninguém entendeu o motivo desta internação, a não ser eu mesma: necessitava desesperadamente de amor e proteção. Estava magra, nervosa e não dormia. O sanatório parecia-me romântico e belo. Havia certo mistério que me atraía (CANÇADO, 1991, p. 62).
}

Como se nota, a experiência com o hospício vai de encontro às suas expectativas, deixando-a em constante estado de tensão. Se no início do diário a narradora explica que a sua 
relação com Deus configura-se em sentimento de medo, ela estende essa sensação ao hospício, porque, para ela, "Hospício é não se sabe o quê, porque Hospício é deus" (CANÇADO, 1991, p. 28).

A partir dos registros datados, que iniciam em 25 de outubro de 1959 e terminam no dia 7 de março de 1960, a narradora Maura põe-se a relatar fatos cotidianos relacionados à sua internação no Hospital Psiquiátrico Gustavo Riedel, em Engenho de Dentro, Rio de Janeiro, revelando os bastidores do hospício, formulando opiniões sobre o fazer médico e expondo sentimento de perplexidade e dúvidas a respeito dos diagnósticos.

A sua internação nesse hospício se dá de modo voluntário, por um estranhamento profundo com o mundo dos "normais". Antes disso, ainda em Belo Horizonte, Minas Gerais, os excessos de Maura levaram-na a gastar toda a herança. Na década de 1950, muda-se, então, para o Rio de Janeiro, indo trabalhar primeiramente no Ministério da Educação e, em seguida, entre 1958 e 1961, torna-se colaboradora no Jornal do Brasil, na seção do Suplemento Dominical do Jornal do Brasil, o SDJB, publicando contos e poemas. Sua chegada ao Rio de Janeiro está registrada no diário na data de 16 de dezembro de 1959: Nessa época, a narradora afirma que passou por recorrentes crises depressivas que a levaram à sua internação na Casa de Saúde do Alto da Boa Vista e no Sanatório da Tijuca.

Vivi um ano com muito dinheiro, em completo desequilíbrio psíquico. Não aceitava
aquela situação, sobretudo pela minha dependência financeira. Sempre ameaçada por
uma crise, tomada de completa depressão (passava vinte ou mais dias trancada em
meu apartamento de hotel, ouvindo música e chorando), ou muita exaltação, fiz um
eletroencefalograma, que acusou disritmia cerebral generalizada (CANÇADO, 1991,
p. 99).

Tal como relata no diário, as recorrentes crises de esquizofrenia levam Maura a experienciar a rotina do hospício, de cuja convivência fez solo para sua escrita. Em 1972, em uma de suas internações que acontece na Casa de Saúde Dr. Eiras, Maura torna-se a principal suspeita de matar uma paciente por estrangulamento. No entanto, por sua condição mental, foi considerada inimputável pela justiça e condenada a viver em um hospital de custódia. Por não haver hospitais prisões femininos no Rio de Janeiro, Maura foi levada entre uma prisão e outra.

Em 1978, Margarida Autran visita Maura na Penitenciária Lemos de Brito e escreve um relato pungente sobre a situação em que se encontrava a escritora. A entrevista, que consta na edição de 1991 de Hospício é deus, quando publicada como matéria no jornal O Globo, causa tamanha comoção no meio artístico, levando parte de seus antigos colegas escritores do Jornal do Brasil, entre eles José Louzeiro, Nélida Piñon, Antônio Houaiss, Rubem Fonseca, Cícero 
Sandroni e Evaristo de Morais Filho, a formarem uma comissão, pelo Sindicato dos Escritores do Município do Rio de Janeiro, que solicitou a transferência de Maura para a Casa de Repouso Corcovado, em Jacarepaguá. Maura fica lá até 1980, ganhando, depois disso, liberdade vigiada. Não escrevia mais. Morreu em 19 de dezembro de 1993, em razão de uma doença pulmonar.

Percebe-se no diário de Maura um projeto narrativo autorreferente no qual pretende mais do que consignar seus atos; há um desejo de denunciar ao mundo a situação de descaso e violência à qual eram submetidas as mulheres loucas pelo estado brasileiro. Posicionando-se em relação ao seu tempo como vítima do poder psiquiátrico, Maura tem sua voz legitimada no espaço de fala do louco produtivo, encerrando em sua obra uma denúncia contra o Estado: "com o que escrevo poderia mandar aos "que não sabem" uma mensagem do nosso mundo sombrio" (CANÇADO, 1991, p. 31).

A experiência de sofrimento do hospício acarreta em Maura escritos de urgência, em um claro desejo de dar sentido à sua existência. Para tanto, ainda que de forma dolorosa - já que elege o diário - faz-se em texto, afirmando: "Pretendo mesmo escrever um livro. Talvez já o esteja fazendo, não queria vivê-lo" (CANÇADO, 1991, p. 55). E é com a escrita de si que evidencia o gesto de coragem, pois é em primeira pessoa que desafia o poder institucional e sociedade, declarando seu desejo de denunciar a marginalidade dos loucos: "Gostaria de escrever um livro sobre o hospital e como se vive aqui. Só quem passa anonimamente por este lugar pode conhecê-lo" (CANÇADO, 1991, p. 55).

A constituição da Maura narradora se dá mediante a pluralidade da voz, representando a situação de uma coletividade. O sentido do "pré-construído ideológico" do seu dizer é construído a partir da vida, da exterioridade de um discurso que é também o discurso de todos os pacientes de hospícios que sofreram os horrores da psiquiatria durante a primeira década do século XX no Brasil. Evidenciam-se na obra relatos de abusos praticados pelo poder psiquiátrico que foram determinantes na constituição das identidades dos sujeitos que nela emergem. A pluralidade do discurso apoiada por uma interpelação histórica sedimenta o objetivo da literatura, que é "escrever por esse povo que falta... ('por' significa 'em intenção de' e não 'em lugar de')” (DELEUZE, 1997, p. 15).

\section{Considerações finais}

Maura produz uma obra cujos relatos mostram-se fragmentados, divididos em instantes descontínuos. Tempo e narrativa na escrita de Maura vão perdendo antigas representações (a 
partir da unidade do eu) e lentamente seu fio de continuidade e de memória (não é mais o tempo sucessão que está em jogo). Como afirma Custódio, nas obras de Maura

\begin{abstract}
a própria narrativa autoficcional se ocupa em tornar impossível qualquer linearidade, qualquer suposição de verossimilhança com o que possa ser um diário. Talvez, para agravar o falseamento, de repente para deixar claro sua intenção de subverter e quebrar várias regras, Maura deixa um livro em aberto. Um diário marcado pela inconclusão, como marca ainda mais forte de que a autoficção nunca termina com um ponto final. E neste formato abalado pelo abismo da ambiguidade há um "eu" que continua escrevendo para além de si mesmo, para além de qualquer ficcionalidade: o narradorautor (ou autor-narrador?) (CUSTÓDIO, 2017, p. 35).
\end{abstract}

É o acontecimento marcando as convergências e as divergências de todos os elementos de uma relação e sua expressão narrativa. Assim, Maura tece um diário em que passado e presente, reconstituídos por uma escrita que oscila entre factual e ficcional, encontram-se imbricados no corpo da narrativa. São as múltiplas imagens na superfície de um campo de experiência tornando-se sentido e constituindo em Maura Lopes Cançado uma "outra" noção de realidade.

Maura, produtivamente, faz-se a própria temática da loucura na obra. Em seu diário, transparece o seu sentimento de não pertencer a lugar nenhum. A solidão e o medo encontram nas 'flores frias' do hospício um meio de "fugir para algum lugar, aparentemente fora do mundo" (CANÇADO, 1991, p. 28). Vê-se que, no meio feminino literário, a loucura não é um tema novo, contudo é com Maura que se inicia a escrita produtiva feminina do louco, pois, na percepção (absolutamente sensível) que Ela tem do passado, é afetada pela sua relação com os eventos presentes, uma certa contração do tempo, não como uma evocação de um passado, para fins de uma reconstrução. Não é disso que se trata. Falamos de um passado redescoberto, mas este, munido de novas percepções e experimentações; partindo de memórias que ocorrem e surgem no intuito de reforçar a relação de oposição existente entre um possível mundo reconfortante, que está no passado, e um mundo repleto de conflitos e violências que representa o presente.

\title{
Referências
}

BLANCHOT, M. O livro por vir. Tradução de Leyla Perrone-Moisés. São Paulo: Martins Fontes, 2005.

BLANCHOT, M. O espaço literário. Tradução de Álvaro Cabral. Rio de Janeiro: Rocco, 2011.

CANÇADO, M. L. O sofredor do ver. Rio de Janeiro: José Álvaro Editor, 1968. 
CANÇADO, M. L. Hospício é deus: Diário I. Rio de Janeiro: Círculo do Livro, 1991.

CANÇADO, M. L. O sofredor do ver. 2. ed. Belo Horizonte: Autêntica Editora, 2015.

CANÇADO, M. L. Hospício é deus: Diário I. 5. ed. Belo Horizonte: Autêntica Editora, 2015.

CASTELLO BRANCO, Lúcia. O feminino ofício de uma escrita delirante. In: A mulher escrita. Rio de Janeiro: Lamparina Editora, 2004.

CUSTÓDIO, M. M. Literatura e loucura: a carnalidade da loucura de Maura Lopes Cançado em Hospício é deus. Dissertação (Mestrado em Letras/Estudos Literários), Universidade Estadual de Montes Claros, Minas Gerais, 2014.

CUSTÓDIO, M. M. A escrita de Maura Lopes Cançado: um contraponto com a (des)articulação da linguagem do louco. Tese (Doutorado em Letras/Estudos Literários), Universidade Federal do Espírito Santo, Espírito Santo, 2017.

DELEUZE, Gilles. Crítica e clínica. Tradução de Peter PálPelbart. São Paulo: 34, 1997.

DELEUZE, G.; GUATTARI, F. Mil Platôs: capitalismo e esquizofrenia. São Paulo: Ed. 34, 1997, v. 4.

FOUCAULT, M. História da loucura: na Idade Clássica. Tradução de José Teixeira Coelho Neto. 9. ed. São Paulo: Perspectiva, 2010.

JARDIM, Alex C.; MAIA, Claudia de Jesus. Loucura e literatura: aproximações entre Lima Barreto e Michel Foucault. Poiesis: Revista de Filosofia, Montes Claros, v. 12, n. 1, 2015, p. $60-73$.

PELBART, P. P. A nau do tempo rei: 7 ensaios sobre o Tempo da Loucura. Rio de Janeiro: Imago. 1993.

Recebido em: 02/06/2019

Aceito para publicação em: 25/11/2019 